\title{
First record of Zaprionus indianus (Gupta, 1970) (Diptera Drosophilidae) from Bangladesh
}

\author{
Sadniman Rahman, Deponkor Kumar Roy \& Mohammad Shamimul Alam* \\ Genetics and Molecular Biology Laboratory, Department of Zoology, University of Dhaka, Dhaka-1000, Bangladesh \\ *Corresponding author, email: shamimul@du.ac.bd
}

\begin{abstract}
Zaprionus indianus (Gupta, 1970) (Diptera Drosophilidae), also known as African fig fly, is considered as the primary pest only to fig fruits along with secondary pest to other fruits. Its occurrence has been reported from many countries but not previously reported from Bangladesh. With this note, we report here the first observation of $Z$. indianus from Bangladesh. Fly samples were collected by using yeast-banana traps. The species was identified by morphological characteristics and mitochondrial COI gene sequence.
\end{abstract}

KEY WORDS African fig fly; Bangladesh; Zaprionus indianus.

Received 05.05.2020; accepted 12.08.2020; published online 30.09.2020

\section{INTRODUCTION}

Zaprionus indianus (Gupta, 1970) (Diptera Drosophilidae), commonly known as African fig fly, belongs to the genus Zaprionus Coquillett, 1902 which contains a total of 57 species (Yassin \& David, 2010). This fly has brown body of approximately 2.5 to $3.0 \mathrm{~mm}$ in length along with red eyes. However, they have a pair of distinctive silvery-white stripes with black borders on the top of the head to the tip of the scutellum as well as laterally from the forefront of the thorax to the base of each wing. Zaprionus indianus was first described from India in 1970 (Gupta, 1970). Though this fly was thought to be originated from tropical Africa (Chassagnard \& Kraaijveld, 1996), at present it has spread in many parts of the world including from old to new world countries (Commar et al., 2012). At present, the geographical distribution of $Z$. indianus is considered as cosmopolitan (Tidon et al., 2003). Though this fly is being reported from different parts of the world including some Asian countries (Commar et al.,
2012), but there is no previous record from Bangladesh.

In this paper, we report the occurrence of Z. indianus from Bangladesh for the first time.

\section{MATERIAL AND METHODS}

Flies were collected during a field sampling from Natore $\left(24^{\circ} 26^{\prime} 26.5^{\prime} \mathrm{N}\right.$; 8900'36.7' E), a northern district of Rajshahi division of Bangladesh (Fig. 1). Yeast-banana traps were used to collect them. Flies were reared and maintained on food made with semolina yeast. Morphological identification was done by observing the 4 to 6 composite spines on the fore femur along with the prominent pair of silvery-white stripes (Gupta, 1970). For further confirmation, molecular identification was conducted by partially sequencing the mitochondrial COI gene. Universal primer pairs LCO1490 (forward) and HCO2198 (reverse) were used for PCR amplification after extracting the DNA (Folmer et al., 1994). Sequence file was submitted to 


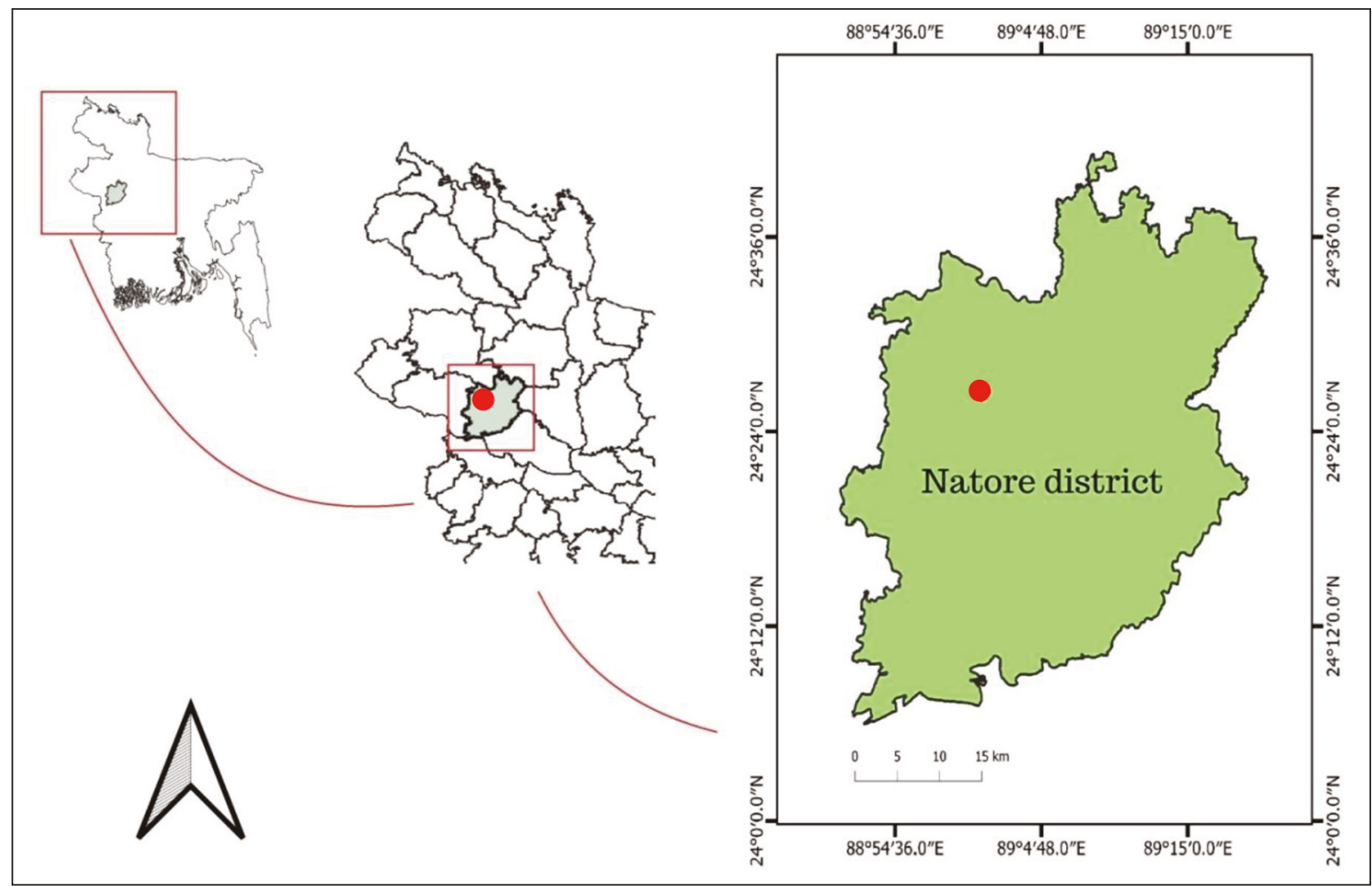

Figure 1. Distribution of Zaprionus indianus in Bangladesh. The red dot denotes the exact location from where the fly was collected.

NCBI GenBank (Accession no. MN863530.1). Specimens were preserved at the Genetics and Molecular Biology Laboratory, Department of Zoology, University of Dhaka.

\section{RESULTS}

\section{Systematics}

Phylum ARTHROPODA von Siebold, 1848 Classis INSECTA Linnaeus, 1758 Ordo DIPTERA Linnaeus, 1758 Familia DROSOPHILIDAE Róndani, 1856 Genus Zaprionus Coquillett, 1902

\section{Zaprionus indianus (Gupta, 1970) Figs. 2-4}

Collected flies were first identified as Z. indianus by observing the longitudinal silvery-white stripes (Fig. 2) along with the spines on the fore femur (Fig. 3) (Gupta, 1970). This was further confirmed by the result of partial sequencing of the mitochondrial COI gene. Amplified sequence was approximately 630 bp in length. Basic Local Alignment Search Tool (BLAST) of National Center for Biotechnology Information (NCBI) was used to check similarity between our sequence and GenBank database of sequences. BLAST result revealed that our observed sequence showed $99.52 \%$ similarity with the sequence of $Z$. indianus in GenBank from Israel and India (Accession no. KC994626.1 and EF632366.1 respectively) along with 99.37\% similarity with the sequences of the same species in GenBank from India, Saudi Arabia and Egypt (Accession no. EF632367.1, EF632365.1 and EF632362.1 respectively). This confirmed that our collected species is Zaprionus indianus.

\section{DISCUSSION AND CONCLUSION}

Zaprionus indianus is reported as primary pest only to fig fruits along with secondary and a serious aggressive pest to more than 80 different fruits 


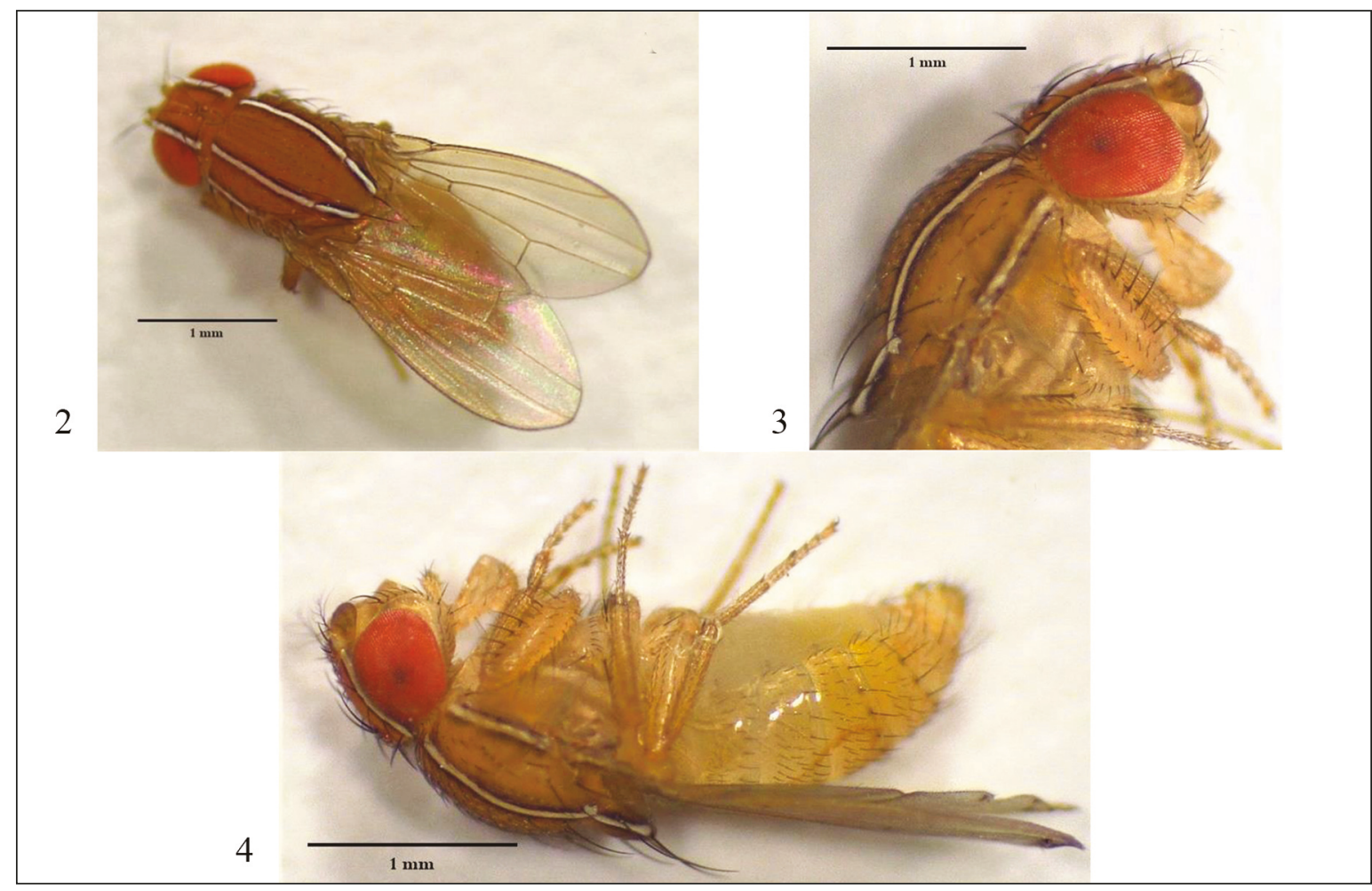

Figure 2. Zaprionus indianus (Gupta, 1970) collected from Natore, Bangladesh, dorsal view.

Figure 3. Idem, composite spines on the fore femur. Figure 4. Idem, lateral view.

(Yassin \& David 2010; Van der Linde et al., 2006). Being considered as cosmopolitan species, this fly is widely distributed throughout many different countries of the world (Karan et al., 2000). It was thought that the genus Zaprionus appeared first in the Oriental region during the Late Miocene. Immediately after that, it spread to the West Africa during the Quaternary through the Indian Ocean (Yassin et al., 2008). Most of the morphological and ecological modifications took place there due to different climatic conditions. Global trade of fruits can be a major reason of why they are so widely distributed. As one of the most widespread species of the genus Zaprionus, this species occurs over a broad range in Asia along with Africa and the Americas (Commar et al., 2012). Though its occurrence has been reported from neighboring India and Pakistan (Gupta, 1970; Shakoori \& Butt 1979; Commar et al., 2012), its presence in Bangladesh has not been reported previously. The survey area (Natore under Rajshahi Division) is located at the northern part of Bangladesh near Indian border. Thus it has a great chance that this fly might invade from India either by fruit trading or by other ways. Our present study shows the presence of $Z$. indianus from Bangladesh for the first time. As they have potential role in damaging different fruits, further study will be useful.

\section{ACKNOWLEDGEMENTS}

We are grateful to the local government division of Natore, Rajshahi for allowing us to conduct the field survey. We are thankful to Gyan Sanker Paul and Sristy Saha for helping during the laboratory works. We would also like to thank Arnob Saha for his help with the preparation of the location map.

\section{REFERENCES}

Chassagnard M.T. \& Kraaijveld A.R., 1996. The occurrence of Zaprionus sensu stricto in the Palearctic region (Diptera: Drosophilidae). Annales de la Société entomologique de France (N.S.), 27: 495-496.

Commar L.S., Galego L.G.D.C., Ceron C.R. \& Carareto 
C.M.A., 2012. Taxonomic and evolutionary analysis of Zaprionus indianus and its colonization of Palearctic and Neotropical regions. Genetics and Molecular Biology, 35: 395-406. https://doi.org/10. 1590 /S1415-47572012000300003

Folmer O., Black M., Hoeh W., Lutz R. \& Vrijenhoek R., 1994. DNA primers for amplification of mitochondrial cytochrome c oxidase subunit I from diverse metazoan invertebrates. Molecular Marine Biology and Biotechnology, 3: 294-299.

Gupta J.P., 1970. Description of a new species of Phorticella Zaprionus (Drosophilidae) from India. Proceedings of the Indian National Academy of Sciences, 36: 62-70.

Karan D., Dubey S., Moreteau B., Parkash R. \& David J.R., 2000. Geographical clines for quantitative traits in natural populations of a tropical drosophilid: Zaprionus indianus. Genetica, 108: 91-100. https:// doi.org/10.1023/A:1004090517967

Shakoori A.R. \& Butt U., 1979. Effect of thioacetamide on the development of a drosophilid fly. I. Morphological studies. Pakistan Journal of Zoology, 11: 315328.

Tidon R., Leite D.F. \& Leao B.F.D., 2003. Impact of the colonization of Zapronus indianus (Diptera,
Drosophilidae) in different ecosystems of the Neotropical region: 2 years after the invasion. Biological Conservation, 112: 299-305. https://doi.org/ 10.1016/S0006-3207(02)00322-1

Van der Linde K., Steck G.J., Hibbard K., Birdsley J.S., Alonso L.M. \& Houle D., 2006. First records of $\mathrm{Za}$ prionus indianus (Diptera; Drosophilidae), a pest species on commercial fruits from Panama and the United States of America. Florida Entomologist, 89: 402-404.

Yassin A., Araripe L.O., Capy P., Da Lage J.L., Klaczko L.B., Maisonhaute C., Ogereau D. \& David J.R., 2008. Grafting the molecular phylogenetic tree with morphological branches to reconstruct the evolutionary history of the genus Zaprionus (Diptera, Drosophilidae). Molecular Phylogenetics and Evolution, 47: 903-915.

Yassin A. \& David J.R., 2010. Revision of the Afrotropical species of Zaprionus (Diptera: Drosophilidae), with descriptions of two new species and notes on internal reproductive structures and immature stages. Zookeys, 51: 33-72. https://doi.org/10.3897/zoo keys. 51.380 